\title{
Cationic Conductivity of Blend Complexes Composed of Poly[oligo(oxyethylene) methacrylate] and the Alkali Metal Salts of Poly(sulfoalkyl methacrylate)
}

\author{
Shengshui ZHANG, Zhenghua DENG, and Guoxiang WAN* \\ Chengdu Institute of Organic Chemistry, Academia Sinica, \\ Chengdu 610015, China
}

(Received May 21, 1990)

\begin{abstract}
Two kinds of alkali metal salts of poly(sulfoalkyl methacrylate)s (PSAMM) were prepared, with which the blend complexes of poly[oligo(oxyethylene) methacrylate] $\left(\mathrm{PMEO}_{n}\right)$ were formed. These blend complexes contain neither organic plasticizer nor low molecular weight Li-salt and are considered to be single-cationic conductors which are characterized by stable dc ionic conductivity. Cationic conductivity is deeply influenced by the glass transition temperature, cation species, polar group (acrylonitrile), the concentration of polymeric salts, and the size of side-group in PSAMM. An optimum $\mathrm{Li}^{+}$-ionic conductivity of $1.1 \times 10^{-6} \mathrm{~S} \mathrm{~cm}^{-1}$ at $25^{\circ} \mathrm{C}$ is obtained for the blend complex $\mathrm{P}\left(0.6 \mathrm{MEO}_{18}-0.4 \mathrm{AN}\right) / \mathrm{P}(0.5 \mathrm{SHMLi}-0.5 \mathrm{AN})$ (AN, acrylonitrile; SHMLi, lithium sulfohexyl methacrylate) with $\mathrm{O} / \mathrm{Li}=72$.

KEY WORDS Comb-Shaped Polyether / Polymeric Salt / Blend Complex /

Cationic Conductivity
\end{abstract}

In recent years the complexes of polyethers with Li-salt have been extensively investigated as polymer electrolyte materials for all-solidstate lithium batteries. ${ }^{1}$ However, most of the polymer electrolytes ever studied are bi-ionic conductors, in which both anion and cation have a chance to move in the opposite directions under dc polarization. This anion motion is quite unfavorable for the application of polymer electrolytes to solid-sate lithium batteries with $\mathrm{Li}^{+}$-insertion type cathode because of the intrapolarization in the electrolytes. $^{1,2}$ A number of investigations demonstrate that ion transport is often dominated by the anion due partly to the chelation of the cation with the immobilized oligo(oxyethylene) ligand. Therefore, it is of great importance to optimize cation transport for high performance dry lithium batteries.

An effective method to immobilize anions

\footnotetext{
* To whom correspondence should be addressed.
}

is to anchor them to polymer chains through covalent bonds, such as plasticized polymeric salt, ${ }^{4}$ the complexes of poly(ethylene oxide) with polymeric salts, ${ }^{5}$ and poly[oligo(oxyethylene) methacrylate-co-alkali metal methacrylate]s ${ }^{2}$ etc. Due to the tight ion pair and strong chelation of cation with ether oxygen atoms, the cationic conductivity in the above systems is relatively low in comparison with the bi-ionic conductors. In the present paper the blend complexes composed on poly[oligo(oxyethylene) methacrylate] $\left(\mathrm{PMEO}_{n}\right)$ with low glass transition temperature $\left(T_{\mathrm{g}}\right)$ and alkali metal salts of poly(sulfoalkyl methacrylate) (PSAMM) were prepared. The correlation between the structure of component polymers and cationic conductivity will be discussed. 


\section{EXPERIMENTAL}

\section{Materials}

Oligo(oxyethylene) methacrylate $\left(\mathrm{MEO}_{n}\right.$, where $n=18$ ) was synthesized as suggested by Philippe et $a l .{ }^{6}$ Oligo(oxyethylene) monomethyl ether with 18 ether oxygen units purchased from Kanto Chemical Co., Ltd. was dried under vacuum at $120^{\circ} \mathrm{C}$ for $24 \mathrm{~h}$ and then, together with an excess of triethylamine, dissolved in dry toluene. Under nitrogen atmosphere a slight excess of methacryloyl chloride in dry toluene solution was added dropwisely to the above solution at $0^{\circ} \mathrm{C}$. This solution was stirred at $0 \mathrm{C}$ for $1 \mathrm{~h}$ followed by further reaction at room temperature for another $16 \mathrm{~h}$. After precipitate was filtered the solution flowed through a silica gel column to remove unreacted methacryloyl chloride and monomethyl ether. Only pure compound fraction was collected, and evaporated carfully below $30^{\circ} \mathrm{C}$ under vacuum. Both IR and ${ }^{1} \mathrm{H}$ NMR spectra of the product demonstrated the same results as reported in the literture,,$^{2.6}$ and elemental analysis found no chloride atoms.

Alkali metal salts of sulfoethyl methacrylates (SEMM) were prepared according to the patent by Sheetz et al. ${ }^{7}$ Sodium 2-hydroxy ethylsulfonate, supplied by Toshiba Silicone Co., was turned to the corresponding free acid by passing its water solution through a $\mathrm{H}^{+}$-type cation exchange resin. After concentrating, the resulting acid was esterified with slight excess methacrylic acid in the presence of hydroquinone as inhibitor at $120^{\circ} \mathrm{C}$ oil-bath. Water formed was withdrawn from reactor from reactor during the reaction by means of azeotropic distillation with toluene. A different alkali metal salt was readily obtained by neutralizing with alkali metal carbonate. The product precipitated on addition of ethyl ether and was purified by recrystallization from methanol/water mixed-solution ( $9: 1$ in volume). The yield was about $65 \%$. The structure was determined by IR and ${ }^{1} \mathrm{H}$ NMR spectra, the ${ }^{1} \mathrm{H}$ NMR results in $\mathrm{D}_{2} \mathrm{O}$ were as follows: 1.92 $\left(3 \mathrm{H},-\mathrm{CH}_{3}\right), 4.54\left(2 \mathrm{H},-\mathrm{COOCH}_{2}-\right), 3.31(2 \mathrm{H}$, $\left.\mathrm{CH}_{2} \mathrm{SO}_{3} \mathrm{M}\right), 5.69,6.15\left(2 \mathrm{H}, \mathrm{CH}_{2}=\right)$.

$\mathrm{C}_{6} \mathrm{H}_{9} \mathrm{SO}_{5} \mathrm{Li}$ :

Calcd C, 60.00\%; H, 4.50\%; S, 16.00\%

Found C, $59.97 \% ; \mathrm{H}, 4.56 \% ; \mathrm{S}, 15.97 \%$.

Alkali metal salts of sulfohexyl methacrylates (SHMM) were prepared according to the route:

$$
\begin{gathered}
\mathrm{HO}\left(\mathrm{CH}_{2}\right)_{6} \mathrm{OH} \stackrel{\mathrm{HCl}}{\longrightarrow} \mathrm{HO}\left(\mathrm{CH}_{2}\right)_{6} \mathrm{Cl} \frac{\mathrm{Na}_{2} \mathrm{SO}_{3}}{N_{2}} \\
\mathrm{HO}\left(\mathrm{CH}_{2}\right)_{6} \mathrm{SO}_{3} \mathrm{Na} \underset{2 . \mathrm{CH}_{2}=\mathrm{C}\left(\mathrm{CH}_{3}\right) \mathrm{COOH}}{\longrightarrow} \\
\stackrel{\mathrm{M}_{2} \mathrm{SO}_{3}}{\longrightarrow} \mathrm{CH}_{2}=\mathrm{C}\left(\mathrm{CH}_{3}\right) \mathrm{COO}\left(\mathrm{CH}_{2}\right)_{6} \mathrm{SO}_{3} \mathrm{M}
\end{gathered}
$$

The synthesis of 6-chlorohexanol was described elsewhere. ${ }^{8}$ The product obtained is a colorless liquid with boiling point $100-102^{\circ} \mathrm{C} / 9 \mathrm{mmHg}$.

Sulfonation of 6-chlorohexanol with sodium sulfite was carried out in the presence of tetrabutyl ammonium hydrosulfate as phase transfer catalyst under nitrogen atmosphere at reflux temperature with vigorous stirring. The resulting product was repeatedly extracted with $95 \%$ alcohol. Total yield vs. 6-chlorohexanol was $75-80 \%$. ${ }^{1} \mathrm{H}$ NMR. result in $\mathrm{D}_{2} \mathrm{O}$ was $1.7-2.3\left(8 \mathrm{H},-\mathrm{CH}_{2}\left(\mathrm{CH}_{2}\right)_{4} \mathrm{CH}_{2}-\right), 3.2(2 \mathrm{H}$, $\left.\mathrm{HOCH}_{2}-\right), 4.0\left(2 \mathrm{H},-\mathrm{CH}_{2} \mathrm{SO}_{3} \mathrm{Na}\right)$.

$$
\begin{aligned}
& \mathrm{C}_{6} \mathrm{H}_{13} \mathrm{O}_{4} \mathrm{SNa} \text { : } \\
& \text { Cacld C, } 35.28 \% ; \mathrm{H}, 6.27 \% ; \mathrm{S}, 15.72 \% \text {. } \\
& \text { Found C, } 34.84 \%, \mathrm{H}, 6.40 \% ; \mathrm{S}, 15.92 \% \text {. }
\end{aligned}
$$

The preparation procedure of SHMM from alkali metal 6-hydroxyhexyl sulfonate was the same as that of SEMM.

All involved polymers were prepared as follows. Given amounts of monomer and AIBN ( $1 \mathrm{~mol} \%$ to the total vinyl monomers) were dissolved in dry methanol. The solution was thorougly frozen-degassed on a vacuum line, and ampoule was sealed off followed by polymerization for $16 \mathrm{~h}$ in $60^{\circ} \mathrm{C}$ water-bath. The polymers were precipitated on addition of 20 times their volume of ether, and dried at $80 \mathrm{C}$ under vacuum. The composition of copolymers was determined by elemental 
analysis.

\section{Preparation of Blend Complexes}

Dissolution of the polymeric salts in the polyether was achieved by adding both to dry methonal followed by evaporation of the solvent. Resulting sample were dried at $120^{\circ} \mathrm{C}$ for $40 \mathrm{~h}$ under vacuum. The composition of the blend complexes was expressed in terms of ethylene oxide units per cation $(\mathrm{O} / \mathrm{M})$.

\section{Measurements}

All measurements were carried out under dry nitrogen atmosphere.

Ac conductivity was measured as described elsewhere ${ }^{9}$ using a $1.10 \mathrm{kHz}$ ac conductometer. Conductivity was determined at each temperature after equilibration for $20 \mathrm{~min}$ following each incremental rise. Dc conductivity measurement, in which lithium electrodes were utilized, was made by applying a constant voltage $(2.0 \mathrm{~V})$ over the cell and recording the current with a millivolt ammeter (Model WDZ-1, made by Shanming Radio Works).

A Perkin-Elmer DSC-7 differential scanning calorimeter was used to evaluate the glass transition temperature $\left(T_{\mathrm{g}}\right)$ and the melting point of the oligoether crystalline $\left(T_{\mathrm{m}}\right)$. The $T_{\mathrm{g}}$ was taken as the temperature at the midpoint of the base-line shift observed during the transition from the glass to the rubber-like state.

\section{RESULTS AND DISCUSSION}

\section{Composition Effect on the Glass Transition Temperature}

Both PSHMM and PSEMM are glass state polymers with a $T_{\mathrm{g}}$ ranging from 245 to $265^{\circ} \mathrm{C}$. Generally PSHMM has relatively lower $T_{\mathrm{g}}$ due to its flexible, longer side-group, the $T_{\mathrm{g}}$ of PSHMLi and PSEMLi are 254 and $265^{\circ} \mathrm{C}$, respectively. After complexation of the PSAMM with $\mathrm{PMEO}_{n}$ a new $T_{\mathrm{g}}$ substitutes the original $T_{\mathrm{g}}$ of either PSAMM or $\mathrm{PMEO}_{n} \cdot \mathrm{PCM}$ (phase contrast microscopy) photos show no phase

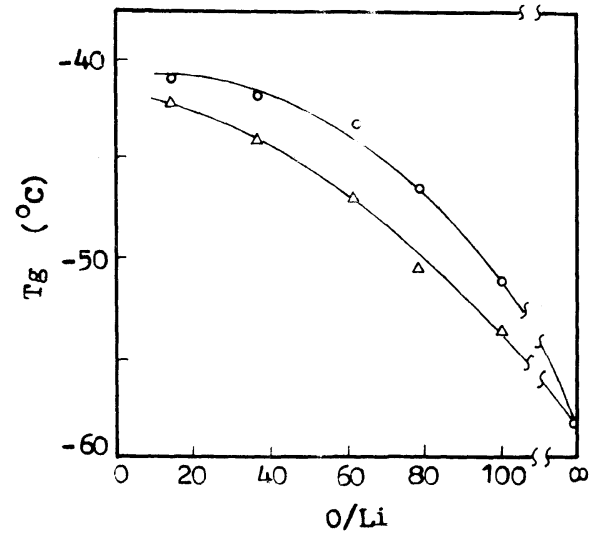

Figure 1. Composition dependence of $T_{\mathrm{g}}$ for the $\mathrm{PMEO}_{18} / \mathrm{PSAMLi}$ blend complex: -O-, $\mathrm{PMEO}_{18}$ PSHMLi; $-\triangle-$ PMEO $_{18} /$ PSEMLi.

separation. Both facts suggest that the blend complex is highly compatible. Contrary to the $T_{\mathrm{g}}$ of PSAMLi themselves the $T_{\mathrm{g}}$ of the blend complex $\mathrm{PMEO}_{18} / \mathrm{PSHMLi}$ demonstrates higher in comparison with $\mathrm{PMEO}_{18} / \mathrm{PSEMLi}$ as shown in Figure 1. In the comb-shaped polyether Li-salt complexes it is common that the dissolution of salts into polyether matrix increases the $T_{\mathrm{g}}$ value owing to the intermolecular and intramolecular crosslinking of the side-chain through the interaction with the cation. ${ }^{9}$ In the present work the similar behavior is also observed. The $T_{\mathrm{g}}$ increases rapidly at first when either PHMLi or PSEMLi is added but slows down to approach a plateau value of $T_{\mathrm{g}}$ as the system reaches saturation. At the same $\mathrm{O} / \mathrm{Li}$ value the higher $T_{\mathrm{g}}$ of the $\mathrm{PMEO}_{18} / \mathrm{PSHMLi}$ can be attributed to the higher tightness of oligo(oxyethylene) segments owing to the longer side-group of the PSHMLi, which is sterically favorable for the chelation of cation with ether oxygen atoms. The increase in $T_{\mathrm{g}}$ at $\mathrm{O} / \mathrm{Li}$ value of about 16 is between 15 and $20^{\circ} \mathrm{C}$ which is comparable with other bi-ionic PMEOn Li-salt complexes ${ }^{9}$. This fact implies that $\mathrm{Li}^{+}$-ion interacts with ether oxygen atoms in the similar manner as the bi-ionic system and that $\mathrm{Li}^{+}$-conductivity should be high in the present system. 
Structural Influence of Polymer Salts on the Conductivity

At the same $\mathrm{O} / \mathrm{Li}$ value the higher $T_{\mathrm{g}}$ of the $\mathrm{PMEO}_{18} / \mathrm{PSHMLi}$ blend complex as compared with the $\mathrm{PMEO}_{18} / \mathrm{PSEMLi}$ implies greater tightness of molecular chains caused probably by the more effective complexation of lithium ion with oligoether side-chains, however, is reflected by the higher conductivity as summarized in Figure 2. This phenomenon is in contrast to the general observations in the bi-ionic systems. The dissolution of PSAMLi into $\mathrm{PMEO}_{18}$ increases the carrier number, but so does the micro-vicosity of the conduction column because of the interaction between lithium ion and ether oxygen in polyether matrix, which leads to a decrease in the mobility of the carrier ions. Combination of above two contrary factors yields an optimum salt concentration for cation conduction. In the $\mathrm{PMEO}_{18} / \mathrm{PSAMLi}$ blend complexes the same carrier source $\left(-\mathrm{SO}_{3} \mathrm{Li}\right)$ determines a similar optimum salt concentration range. Over the $\mathrm{O} / \mathrm{Li}$ value range of $70-90$ two kinds of the blend complexes reach the highest cationic conductivity value. On the other hand, the cation species also influences cationic conductivity. In order to compare the dependence of conductivity on cation species, the conductivity measurement results of the blend complexes with different metal ions were described in Figure 3. The cationic conductivity increases in the order of $\mathrm{Li}<\mathrm{Na}<\mathrm{K}$ in agreement with the order of metal ionic radius. i.e., the conductivities of the $\mathrm{PMEO}_{18} / \mathrm{PSHMM}$ at $25^{\circ} \mathrm{C}$ are $1.8 \times 10^{-7}, 8.2 \times 10^{-7}$, and $1.2 \times 10^{-6}$ $\mathrm{S} \mathrm{cm}^{-1}$ for $\mathrm{Li}^{+}, \mathrm{Na}^{+}$, and $\mathrm{K}^{+}$ion, respectively. This behavior can be explained by the effect of metal ionic radius on the dissociation energy of corresponding salt and the interaction between metal ion and ether oxygen. When PSAMM with larger cationic redius is added, the caductivity should shift to high value because of the lower dissociation energy of its salt and weaker interaction of cation with oligoether segment favorable for cation con-

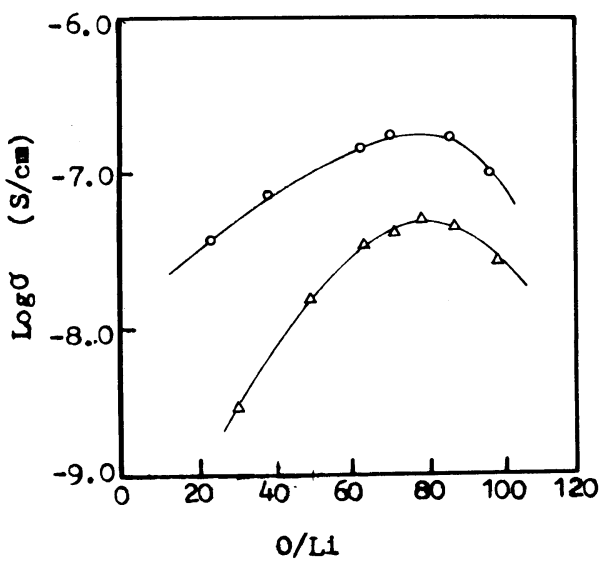

Figure 2. Composition dependence of $\mathrm{Li}^{+}$-ionic conducţivity for the $\mathrm{PMEO}_{18} / \mathrm{PSAMLi}$ blend complex at $25^{\circ} \mathrm{C}$ : $-\mathrm{O}-$, PSHMLi; $-\triangle-$, PSEMLi.

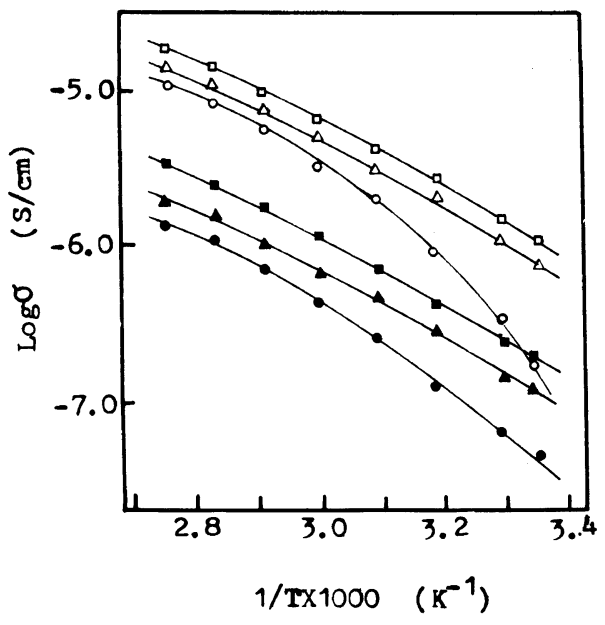

Figure 3. Arrhenius plots of cationic conductivity for the $\mathrm{PMEO}_{18} /$ PSAMM blend complexes with different metal ion and side-group in PSAMM, all with $\mathrm{O} / \mathbf{M}=72$. PSHMM: $\bigcirc, \mathrm{Li} ; \triangle, \mathrm{Na} ; \square, \mathrm{K}$. PSEMM: ○, Li; $\boldsymbol{\Delta}, \mathrm{Na}$; a, K.

duction.

\section{Effect of Polar Acrylonitrile (AN) Group on Conductivity}

The introduction of $\mathrm{AN}$ groups into the molecular chains of the $\mathrm{PMEO}_{18}$ can relieve the crystallization of oligoether side-chain, increase the amorphous region responsible for the ionic conduction and enhance the 
polarity of polymer matrix favorable for the dissociation of the added salts, as a result, improve the conductivity of PMEOn/Li-salt complexes. ${ }^{10}$ However, excessive AN incapable of conplexing with lithium ion will hinder conduction coulmn for ion mobility. Interaction of above factors determines a particular AN content, in which the AN-containing complex shows an optimum conductivity. The most proper AN content usually ranges between 40 and $50 \mathrm{~mol} \%{ }^{10}$ DSC results indicate that the introduction of $\mathrm{AN}$ group decreases both crystallinity and melting point $\left(T_{\mathrm{m}}\right)$ of oligo(oxyethylene) side-chain in $\mathrm{PMEO}_{n}$, such as the $T_{\mathrm{m}}$ of $\mathrm{P}\left(0.6 \mathrm{MEO}_{18}-0.4 \mathrm{AN}\right)$ shifts to $31^{\circ} \mathrm{C}$ from the initial $38^{\circ} \mathrm{C}$ without $\mathrm{AN}$ group. Figure 4 shows that below $30^{\circ} \mathrm{C}$ both the blend complexes $\mathrm{P}\left(0.6 \mathrm{MEO}_{18}-0.4 \mathrm{AN}\right)$ / PSHMLi and $\mathrm{PMEO}_{18} / \mathrm{P}(0.5 \mathrm{SHMLi}-0.5 \mathrm{AN})$ have a little higher conductivity than that without AN group, while at elevated temperature the former becomes lower than $\mathrm{PMEO}_{18} /$ PSHMLi due probably to the poorer intraplasticization of the AN group caused by the melting of side-chain oligoether crystalline. Above results indicate that polar AN group attached to the molecular chains of either $\mathrm{PMEO}_{18}$ or PSHMLi can effectively promote lithium ionic conductivity of the blend complexes at room temprature. Thus the blend complex $\mathrm{P}\left(0.6 \mathrm{MEO}_{18}-0.4 \mathrm{AN}\right) / \mathrm{P}(0.5 \mathrm{SHMLi}-$ $0.5 \mathrm{AN}$ )with both component polymers containing polar AN group has much higher conductivity than all blend complexes discussed above over an extended temperature range from 25 to $90^{\circ} \mathrm{C}$. For example, at $25^{\circ} \mathrm{C}$ its $\mathrm{Li}^{+}$-ionic conductivity reaches $1.1 \times 10^{-6} \mathrm{~S}$ $\mathrm{cm}^{-1}$, one order of magnitude higher than that of the blend complex $\mathrm{PMEO}_{18} / \mathrm{PSHMLi}$ without AN group.

\section{Time Dependence of DC Ionic Conductivity}

The time dependence of the apparent dc ionic conductivity calculated from the change in current with time under an applied voltage of $2.0 \mathrm{~V}$ for the $\mathrm{PMEO}_{18} / \mathrm{LiClO}_{4}$ complex

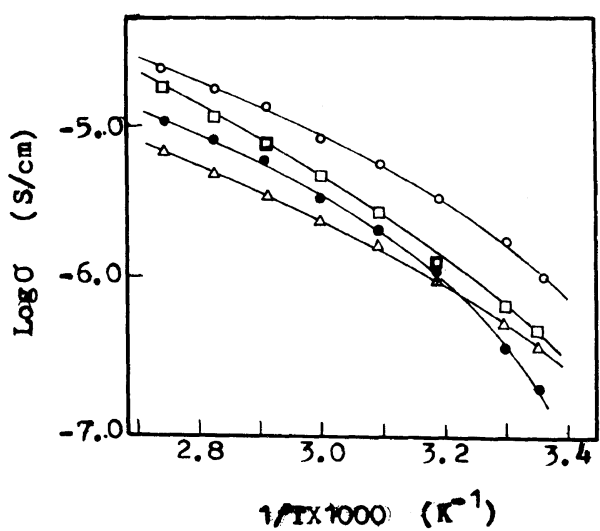

Figure 4. Arrhenius plots of $\mathrm{Li}^{+}$-ionic conductivity of the blend complexes, (1) $\mathrm{PMEO}_{18} / \mathrm{PSHMLi}_{(-)}$, (2) $\mathrm{PMEO}_{18} / \mathrm{P}$ (0.5SHMLi-0.5AN) ( $\square$ ), (3) $\mathrm{P}\left(0.6 \mathrm{MEO}_{18}\right.$ $0.4 \mathrm{AN}) / \mathrm{PSHMLi}(\triangle)$, (4) $\mathrm{P}\left(0.6 \mathrm{MEO}_{18}-0.4 \mathrm{AN}\right) /$ $\mathrm{P}(0.5 \mathrm{SHMLi}-0.5 \mathrm{AN})(\mathrm{O})$, all with $\mathrm{O} / \mathrm{Li}=72$.

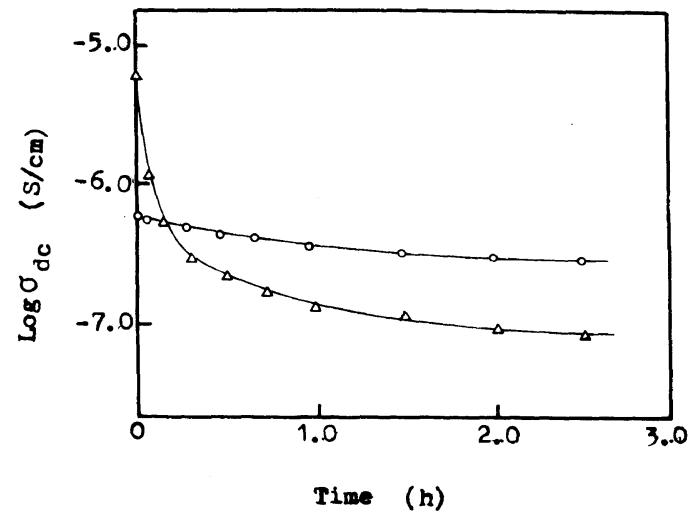

Figure 5. Time dependence of dc $(2.0 \mathrm{~V})$ ionic conductivity in polymer solid electrolyte at $25^{\circ} \mathrm{C}: \triangle, \mathrm{PMEO}_{18} /$ $\mathrm{LiCO}_{4} ; \mathrm{O}, \mathrm{P}\left(0.6 \mathrm{MEO}_{18}-0.4 \mathrm{AN}\right) / \mathrm{P}(0.5 \mathrm{SHMLi}-0.5 \mathrm{AN})$.

with $\mathrm{O} / \mathrm{Li}=18\left(\sigma_{\mathrm{ac}}=2.0 \times 1.0^{-5} \mathrm{~S} \mathrm{~cm}^{-1}\right)$ and the blend complex $\mathrm{P}\left(0.6 \mathrm{MEO}_{18}-0.4 \mathrm{AN}\right) /$ $\mathrm{P}(0.5 \mathrm{SHMLi}-0.5 \mathrm{AN})$ is illustrated in Figure 5. At first the former gives very high ionic conductivity which, however, rapidly decreases with time under de polarization, showing a typically bi-ionic property, i.e., both $\mathrm{Li}^{+}$and $\mathrm{ClO}_{4}{ }^{-}$are mobile toward corresponding electrode although the mobilities are different. This phenomenon can be explained as the polarization of the anion $\left(\mathrm{ClO}_{4}{ }^{-}\right)$since lithium electrode is a non-blocking electrode for $\mathrm{Li}^{+}$ 
ions but a blocking electrode for the anions. With polarization time the effective potential across the electrolyte will decrease due to the formation of the polarized potential opposite to applied voltage and as a result, lead to an initial steep decrease in dc ionic conductivity because of the saturated polarization of the anions. While in the later, where anions bonded covalently to polymer chain are immobile, it is structurally reasonable to be considered as a single-cationic conductor. A stable dc Li-ionic conductivity of about $6.0 \times 10^{-7} \mathrm{~S} \mathrm{~cm}^{-1}$ verifies this supposion, although lower than as ionic conductivity by a charge transfer resistance $\left(R_{\mathrm{e}}\right)$, where the slight decrease in $\mathrm{dc}$ conductivity might result from the orientation of dipoles within the blend complex.

\section{REFERENCES}

1. M. A. Ratner and D. F. Shriver, Chem. Rev., 18, 109 (1988).

2. H. Ohno and E. Tsuchida, J. Macromol. Sci.-Chem., A26, 511 (1988).

3. J. F. Le Nest, A. Gandini, and H. Cheradame, $B r$. Polym. J., 3, 20 (1988).

4. L. C. Hardy and D. F. Shriver, Macromolecules, 17, 975 (1984).

5. D. J. Bannister, G. R. Davies, I. M. Ward, and J. E. Mclntye, Polymer, 25, 1291 (1984).

6. G. Pilippe and F. Yves, Polym. Commun., 27, 16 (1986).

7. D. P. Sheetz and M. Mich, US. Patent, 3.147.301 (1964).

8. K. N. Campbll and A. H. Sommers, Org. Synth. Coll. Vol., 3, 446 (1955).

9. J. M. G. Cowie and A. C. S. Martin, Polym. Commun., 26, 298 (1985)

10. K. Xu, Z. H. Deng, S. S. Zhang, Y. G. Zheng, and G. X. Wan, Preprints, Symposium on Polymer Science, Chengdu, China, p 591. 